\title{
Estado inflamatorio en el angor inestable e infarto de miocardio sin elevación del segmento ST. Valor de la proteína C-reactiva ultrasensible
}

\author{
S. BORRÁS PALLÉ, E. GÓMEZ MARTÍNEZ, A. ROMERO RODRIGO, C. CAMPOS \\ FERRER, E. MOLINA*, V. VALENTÍN SEGURA
}

Unidad de Cuidados Intensivos y *Laboratorio. Hospital Universitario Dr. Peset. Valencia

\begin{abstract}
INFLAMMATORY STATE IN UNSTABLE ANGINA AND MYOCAR DIAL INFARCTION WITHOUT ST SEGMENT ELEVATION. VALUE
\end{abstract} OF HIGH-SENSITIVE C-REACTIVE PROTEIN

\section{RESUMEN}

Objetivos: Analizar el estado inflamatorio en el Síndrome coronario agudo sin elevación del segmento ST mediante el valor de la Proteína CReactiva Ultrasensible y otros marcadores de inflamación. Determinar si hay diferencias entre la angina inestable y el infarto miocardio y si se relaciona con la aparición de complicaciones cardiovasculares en el seguimiento a un año.

Pacientes y métodos: Se estudiaron 61 pacientes diagnosticados de Síndrome coronario agudo sin elevación del ST (SCA): edad media $67 \pm$ 11 años, $26 \%$ mujeres. Se analizó el valor de la Proteína C-reactiva ultrasensible y otros marcadores de inflamación (leucocitos y fibrinógeno) y se compararon pacientes con Angor inestable frente a Infarto agudo de miocardio sin elevación del ST. Seguimiento durante un año de complicaciones cardiovasculares (muerte de origen cardiaco, infarto, isquemia refractaria o rehospitalización por causa cardiovascular) y su relación con los marcadores inflamatorios.

Resultados: El 75\% de los pacientes presentaron valores aumentados de Proteína C-reactiva ultrasensible (valor $>2 \mathrm{mg} / \mathrm{l})$. 47 pacientes $(77 \%)$ fueron diagnosticados de Infarto sin elevación ST y el resto de Angina inestable. No hubo diferencias estadísticamente significativas entre ambos subgrupos respecto al valor de la mediana de la Proteína C-reactiva: $4,49 \mathrm{mg} / \mathrm{l}$ en el infarto, frente a $4,50 \mathrm{mg} / \mathrm{l} \mathrm{en} \mathrm{el} \mathrm{angor} \mathrm{(} \mathrm{p}=\mathrm{ns})$ ni tampoco en el porcentaje de pacientes con Proteína C-reactiva elevada (77\% en infarto $v s 71 \%$ en angor). Respecto a otros marcadores inflamatorios (leucocitos y fibrinógeno) tampoco encontramos diferencias entre subgrupos. Ninguno de los marcadores inflamatorios fueron predictivos de aparición del evento combinado al año de seguimiento.

Conclusiones: La Proteína C-Reactiva ultrasensible se encuentra aumentada en los pacientes con síndrome coronario agudo sin ascenso de ST, sin embargo no encontramos diferencias en el estado inflamatorio de los pacientes con Angina inestable frente al Infarto agudo de miocardio sin elevación del ST. Tampoco, en nuestra serie, estos marcadores mostraron valor predictivo sobre la aparición de eventos cardiacos al año.

PALABRAS CLAVE: Angor inestable. Inflamación. Infarto agudo de miocardio sin elevación del segmento ST. Proteína C-reactiva ultrasensible. Síndrome coronario agudo.

\section{ABSTRACT}

Objectives: To analyse the inflammatory state in Acute Coronary Syndromes without ST-segment elevation by means of the value of the High-sensitivity C-reactive protein and other markers of inflammation. To assess if there are differences between unstable angina and myocar dial infarction and if it has prognostic value of cardiovascular complica tions during one year follow up.

Methods: 61 patients diagnosed of Acute Coronary Syndrome wit hout ST-segment elevation were studied: mean age of $67 \pm 11$ years old, $26 \%$ women. The value of high-sensitivity C-reactive protein and other inflammatory markers (leukocytes and fibrinogen) were analysed and were compared in those patients with unstable angina versus myocardial infarction without ST elevation. Follow up during one year of cardiovas cular complications (death with cardiac origin, infarction, refractory ischemia or rehospitalization because of cardiovascular cause) and its relation with the inflammatory markers.

Results: $75 \%$ of the patients showed increased levels of High-sensiti vity $C$-reactive protein $(>2 \mathrm{mg} / \mathrm{l}) .47$ patients $(77 \%)$ were diagnosed of Infarction without ST elevation and the remainders of Unstable Angina. There were no statistically significant differences between subgroups, neither in the median value of the C-reactive protein: $4.49 \mathrm{mg} / \mathrm{l}$ in infarc tion versus $4.5 \mathrm{mg} / \mathrm{l}$ in Angina $(p=n \mathrm{~s})$ nor in the percentage of patients with high levels of $C$-reactive protein $(77 \%$ in infarction versus $71 \%$ in Angina). With regard to the other inflammatory markers (fibrinogen and leukocytes) no differences between subgroups were found. None of the inflammatory markers showed predictive value about the appearance of the composite end-point during one year follow up.

Conclusions: The high-sensitivity $C$-reactive protein is elevated in patients with Acute coronary syndromes without ST-segment elevation, but no difference in the inflammatory state of patients with unstable angina versus myocardial infarction without ST elevation was found. In our series, these markers were not related whit the risk of cardiovascular complications.

KEY WORDS: Unstable angina. Inflammation. Acute Myocardial Infarction without ST segment High-sensitive C-reactive protein. Acute coronary syndrome.

Borrás Pallé S, Gómez Martínez E, Romero Rodrigo A, Campos Ferrer C, Molina E, Valentín Segura V. Estado inflamatorio en el angor inestable e infarto de miocardio sin elevación del segmento ST. Valor de la proteína C-reactiva ultrasensible. An Med Interna (Madrid) 2002; 19: 283-288.

Trabajo aceptado: 5 de marzo de 2002

Correspondencia: S. Borrás Pallé. Unidad de Cuidados Intensivos. Hospital Universitario Dr Peset. Avenida Gaspar Aguilar 90.46017 Valencia. Teléfono: 96-3862526. Fax: 96-3861933. e-mail: sborrass@ terra.es 


\section{INTRODUCCIÓN}

Actualmente están en investigación múltiples factores de riesgo cardiovascular causantes de la aterogénesis, diferentes a los considerados clásicos (hipertensión arterial, diabetes mellitus, dislipemia, tabaquismo, etc.). Entre ellos la inflamación se considera un mecanismo clave en la génesis y progresión de la placa de ateroma (1-3). La Proteína C-reactiva (PCR) es un reactante de fase aguda, de síntesis hepática, que encontramos elevada en los procesos inflamatorios, siendo un marcador preciso de la actividad inflamatoria global del organismo altamente sensible aunque poco específico. La PCR ha sido estudiada ampliamente en relación con la patología coronaria y se ha visto que se encuentra elevada tanto en la angina inestable como en el infarto agudo de miocardio (4-6). Este marcador ha mostrado en numerosos estudios comportarse como factor pronóstico independiente de complicaciones cardiovasculares tanto en población general (7-9) como en pacientes que presentan cardiopatía isquémica estable e inestable previa $(6,10-14)$, además de tener efecto aditivo junto a otros marcadores y factores de riesgo (15-17) o la ergometría (18). Al igual que en el caso anterior, otros marcadores inflamatorios como el fibrinógeno, la proteína sérica A-amiloide y los leucocitos polimorfonucleares, también han mostrado valor pronóstico en la aparición de complicaciones cardiovasculares en la cardiopatía isquémica $(6,19-21)$. Por otro lado, varios estudios muestran que los valores de la proteína C-reactiva están influenciados por fármacos que se emplean habitualmente en los pacientes diagnosticados de cardiopatía isquémica como la aspirina y las estatinas. Esto indica que además del efecto antiagregante en el caso de la aspirina o la disminución en los niveles de lípidos de las estatinas, estos fármacos presentan actividad antiinflamatoria y parte de su efectividad en la reducción de nuevos eventos coronarios viene mediada por esta capacidad de disminuir la actividad inflamatoria, que es por lo demás independiente de sus demás mecanismos de actuación (22-27). Los nuevos métodos de laboratorio altamente sensibles para la medición de la proteína C-reactiva suponen pues una nueva arma en el diagnóstico, la estratificación de riesgo y manejo de los pacientes con Síndrome Coronario Agudo, aunque su uso no está en el momento actual suficientemente extendido en cualquier laboratorio.

En nuestro trabajo se analizó el estado inflamatorio en los pacientes con Síndrome Coronario Agudo sin elevación del segmento ST (SCA) a través de la PCR ultrasensible (PCRus), prototipo de marcador inflamatorio, y otros marcadores de inflamación como los leucocitos, neutrófilos y fibrinógeno. El objetivo principal fue analizar si existían diferencias en el estado inflamatorio que presentan los pacientes diagnosticados de Angor Inestable (AI) frente al Infarto Agudo de Miocardio sin elevación del segmento ST (IAM sin elevación ST), dado que la existencia de tejido necrótico en el área del IAM puede por sí misma incrementar la respuesta inflamatoria. Por último, se evaluó si existía relación entre diferentes marcadores inflamatorios estudiados en la aparición de eventos coronarios en el seguimiento a un año.

\section{PACIENTES Y MÉTODOS}

\section{POBLACIÓN DE ESTUDIO}

Se trata de un estudio observacional, prospectivo, de cohortes, realizado entre julio 1999 y septiembre 2000. Se incluyeron de forma consecutiva 61 pacientes que ingresaron en nuestra Unidad Coronaria con el diagnóstico de SCA sin elevación del segmento ST (grupo SCA): pacientes con dolor torácico de características isquémicas, sin aumento del segmento ST superior a $1 \mathrm{~mm}$ y dentro de las primeras 24 horas desde el episodio isquémico más reciente. Debían presentar cambios electrocardiográficos sugestivos de isquemia aguda o bien elevación de marcadores enzimáticos miocárdicos (Troponina T). El diagnóstico entre Angor Inestable (grupo AI) e Infarto Agudo de Miocardio sin elevación del segmento ST (grupo IAM), de acuerdo con el consenso actual (28), se hizo en función de la elevación de los valores de Troponina $\mathrm{T}$ (valor normal hasta $0,1 \mathrm{ng} / \mathrm{ml})$.

\section{PARÁMETROS ANALIZADOS}

Se analizaron datos clínicos, electrocardiográficos y de laboratorio referentes al episodio que motivó el ingreso. Fueron recogidos además, factores de riesgo cardiovascular, antecedentes cardiacos y medicación intrahospitalaria. Tras consentimiento escrito por parte del paciente, y con la aprobación del comité ético de nuestro hospital, se obtuvo una muestra de sangre en el momento del ingreso (dentro de las 24 horas siguientes al último episodio de dolor torácico) para análisis de marcadores inflamatorios (PCR-us, leucocitos, neutrófilos y fibrinógeno). Estas muestras, para su conservación, fueron congeladas a una temperatura de $-70{ }^{\circ} \mathrm{C}$. Posteriormente se realizaron los controles habituales que incluyen enzimas miocárdicos seriados (CPK, CPK-MB y Troponina T) y electrocardiograma. El método de análisis de la PCR-us fue mediante inmunonefelometría y el valor de normalidad dado por nuestro laboratorio fue de hasta $2 \mathrm{mg} / \mathrm{l}$.

El seguimiento de los pacientes se llevó a cabo a través de entrevista personal, o bien si esta no era posible, mediante llamada telefónica, con una periodicidad trimestral durante un año. Durante este periodo fueron recogidas las complicaciones cardiovasculares, entre ellas el Evento Combinado (EC) donde incluimos la aparición en primer lugar de cualquiera de los siguientes acontecimientos: Muerte de origen cardiaco, Infarto o reinfarto agudo de miocardio, Isquemia Refractaria (recidiva de la clínica anginosa con cambios electrocardiográficos durante el ingreso, o bien dolor torácico de origen isquémico que requiere nuevo ingreso hospitalario, pese a tratamiento médico adecuado) y Rehospitalización por causa cardiaca (excluyendo las situaciones previas).

\section{ANÁLISIS ESTADÍSTICO}

Para el análisis de datos empleamos el paquete estadístico SPSS (Statistical Package for Social Science, version 9.0 para windows). Los datos referidos a los marcadores inflamatorios no siguieron una distribución normal, vienen definidos como medianas y fueron analizados mediante test no paramétricos (U de MannWhitney). Las variables cualitativas se expresan como porcentaje y se analizaron a través del test de la $\chi^{2}$ (o test exacto de Fisher si las frecuencias esperadas eran menores de 5). El estudio de la aparición de la EC en el seguimiento se realizó mediante el test de Kaplan-Meier en el aná- 
lisis univariado en relación con los diferentes marcadores de riesgo y la Regresión de Cox para el multivariante. Se aceptó como significación estadística un valor de $\mathrm{p}<0,05$.

\section{RESULTADOS}

\section{CARACTERÍSTICAS BASALES}

Se incluyeron un total de 61 pacientes con SCA. De ellos $47(77 \%)$ fueron diagnosticados de IAM sin elevación ST y los otros 14 (23\%) de AI, en función de la elevación de las cifras de TroponinaT; los pacientes que fueron diagnosticados de IAM presentaron un ascenso de las cifras de troponina como mínimo del doble del valor de normalidad dado por nuestro laboratorio. Ningún paciente con troponina normal presentó valores elevados de la fracción MB de la CPK, sin embargo $8(17 \%)$ pacientes fueron diagnosticados de IAM en función de elevación de las cifras de troponina, siendo normal el valor de CPK-MB.

La edad media fue de $67 \pm 11$ años. El $26 \%$ de los pacientes fueron mujeres. En la tabla I se exponen los factores de riesgo y los antecedentes cardiovasculares de los

TABLA I

CARACTERÍSTICAS BASALES

\begin{tabular}{lcccc}
\hline & SCA & IAM & AI & p \\
\hline Pacientes & 61 & $47(77)$ & $14(23)$ & \\
Edad (años) & $67 \pm 11$ & $67 \pm 11$ & $65 \pm 11$ & ns \\
Mujeres & $16(26)$ & $12(25)$ & $4(29)$ & ns \\
Hipertensión arterial & $38(62)$ & $28(60)$ & $10(71)$ & ns \\
Diabetes M ellitus & $18(30)$ & $14(30)$ & $4(29)$ & ns \\
Hipercolesterolemia & $27(44)$ & $18(38)$ & $9(64)$ & ns \\
Tabaquismo & $35(57)$ & $27(57)$ & $8(57)$ & ns \\
Angor previo & $21(34)$ & $14(30)$ & $7(50)$ & ns \\
IAM previo & $8(13)$ & $8(17)$ & $0(0)$ & ns \\
Insuficiencia cardiaca & $5(8)$ & $6(13)$ & $0(0)$ & $n s$ \\
ACV "previo" & $5(8)$ & $3(6)$ & $2(14)$ & ns \\
Arteriopatía periférica & $2(3)$ & $2(4)$ & $0(0)$ & ns \\
\hline
\end{tabular}

Los valores se expresan en número absoluto y porcentaje. Edad como media $\pm \mathrm{DE}$.

ACV: Accidente cerebro vascular. Al: Angor Inestable. IAM : Infarto Agudo de M iocardio. SCA: Síndrome Coronario Agudo.

pacientes en global (grupo SCA) y en los dos subgrupos estudiados (AI e IAM sin elevación del ST), no apreciándose diferencias entre ambos respecto a las variables analizadas. En la tabla II se recogen las características clínicas de los pacientes en el momento del ingreso, así como el tratamiento médico administrado durante la hospitalización y las técnicas de intervencionismo diagnósticas o terapéuticas durante el seguimiento, del total de los pacientes y de ambos subgrupos por separado. Destacar que los cambios electrocardiográficos del tipo infradesnivel del segmento $\mathrm{ST} \geq 1 \mathrm{~mm}$ fueron significativamente más frecuentes en aquellos pacientes diagnosticados de IAM respecto del AI $(p=0,03)$, mientras que no hay diferencias en el resto de variables clínicas o en el tratamiento.
TABLA II

VARIABLES CLÍNICAS AL INGRESO Y MEDICACIÓN DURANTE LA HOSPITALIZACIÓN

\begin{tabular}{lcccc}
\hline & SCA & IAM & AI & p \\
\hline Pacientes & 61 & $47(77)$ & $14(23)$ & \\
TAS (mmHg) & 135 & 135 & 137 & ns \\
TAD (mmHg) & 75 & 75 & 70 & ns \\
FC (Ipm) & 70 & 72 & 66 & ns \\
Killip I & $51(83)$ & $38(81)$ & $13(93)$ & ns \\
Descenso ST $\geq 1 \mathrm{~mm}$ & $35(57)$ & $31(66)$ & $4(28)$ & 0.03 \\
Antiagregantes61 & $(100)$ & $47(100)$ & $14(100)$ & ns \\
Heparina* & $61(100)$ & $47(100)$ & $14(100)$ & ns \\
Nitritos & $58(95)$ & $45(96)$ & $13(93)$ & ns \\
Betabloqueantes & $33(54)$ & $24(51)$ & $9(64)$ & ns \\
Calcioantagonistas & $10(16)$ & $8(17)$ & $2(14)$ & ns \\
IECAs & $34(56)$ & $26(55)$ & $8(57)$ & ns \\
Hipolipemiantes & $28(46)$ & $20(43)$ & $8(57)$ & ns \\
\hline
\end{tabular}

Los valores de TAS, TAD y FC se expresan como mediana. El resto de variables como número absoluto y porcentaje.

ACTP: Angioplastia Coronaria Transluminal Percutánea. FC: frecuencia cardiaca. IECAs: Inhibidores de la enzima convertidora de la Angiotensina. Ipm: latidos por minuto. mmHg: milímetros de mercurio. TAD: Tensión arterial diastólica. TAS: Tensión arterial sistólica.

$(*)$ : heparina intavenosa o subcutánea.

\section{MARCADORES INFLAMATORIOS ESTUDIADOS}

En la tabla III se recogen los valores de los diferentes marcadores de inflamación estudiados. El valor de la mediana de la PCR-us fue 4,49 mg/l en el grupo SCA y dicho marcador estuvo elevado (valor superior a $2 \mathrm{mg} / \mathrm{l}$ ) en 46 (75\%) de los pacientes. En el análisis de los subgrupos vemos que la mediana de la PCR-us en el IAM sin elevación ST fue de 4,49 mg/l frente a $4,50 \mathrm{mg} / \mathrm{l}$ en el $\mathrm{AI}(\mathrm{p}=0,77)$. Tal y como se observa en la figura 1 donde se representa la distribución del logaritmo de la PCR en los diferentes grupos de estudio, la distribución de los valores de la PCR-us es homogénea entre el IAM y el AI sin que se objetivaran diferencias estadísticamente significativas entre estos dos grupos. Por otro lado destacar que no hubo diferencias temporales en la extracción de la muestra para el análisis de la PCR-us entre subgrupos, con una mediana de

TABLA III

M ARCADORES INFLAM ATO RIOS EN EL SÍNDROME CORONARIO AGUDO

\begin{tabular}{lcccc}
\hline & SCA & IAM & AI & p \\
\hline Pacientes & 61 & $47(77)$ & $14(23)$ & \\
PCR-us (mg/l)* & 4,49 & 4,49 & 4,50 & ns \\
PCR-us >2mg/l (n/\%) & $46(75)$ & $36(77)$ & $10(71)$ & ns \\
Leucocitos/m/* & 8.900 & 8.900 & 8.800 & ns \\
Neutrófilos/m/* & 5.700 & 5.800 & 5.200 & ns \\
Fibrinógeno $(\mathrm{mg} / \mathrm{dl})^{*}$ & 414 & 412 & 425 & $\mathrm{~ns}$ \\
\hline
\end{tabular}

* Expresados como valor de la mediana.

Al: Angor inestable. IAM : Infarto agudo de miocardio. PCR-us: Proteína C-reactiva ultrasensible. SCA: Síndrome coronario agudo. 


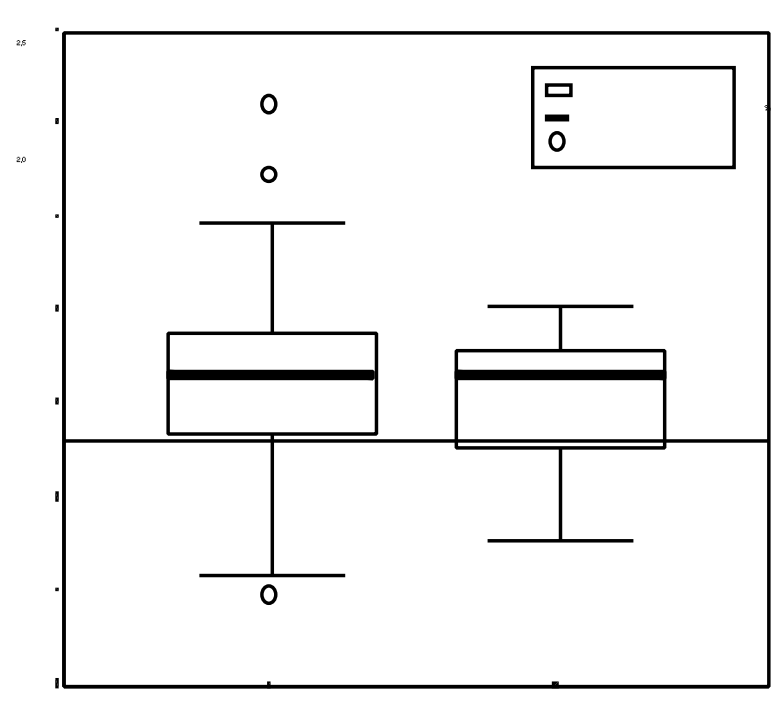

Fig. 1. Distribución de la Proteína C-reactiva ultrasensible en los grupos de estudio. La línea perpendicular al eje de ordenadas representa el valor de referencia de la proteína $C$-reactiva ultrasensible. Al: angor inestable; IAM : infarto Agudo de M iocardio; PCR-us: proteína C-reactiva ultrasensible; $\mathrm{N}$ : número de pacientes en cada grupo.

tiempo de 12 horas para el IAM y 8,5 horas en el AI ( $p=n s)$. Tampoco encontramos diferencias significativas cuando comparamos el porcentaje de pacientes con cifras elevadas de PCR-us entre IAM sin elevación ST: 36 (77\%) versus AI: 10 $(71 \%)(\mathrm{p}=0,73)$. No hubo ningún valor de la PCR-us que sirviera como punto de corte para discriminar entre IAM y AI; el valor del percentil 75 en ambos subgrupos fue similar $(8,17$ $\mathrm{mg} / \mathrm{l}$ en el IAM frente a $6,45 \mathrm{mg} / \mathrm{l}$ en el AI). Cabe destacar que en referencia a los demás marcadores inflamatorios analizados tampoco hubo diferencias entre subgrupos en el caso de los leucocitos, neutrófilos o fibrinógeno.

\section{COMPLICACIONES EVOLUTIVAS}

En la tabla IV se especifican los acontecimientos cardiovasculares acontecidos durante el año de seguimiento, así como el EC: (la primera aparición de muerte, infarto o reinfarto, angina o rehospitalización de causa cardiaca) que aconteció en 21 pacientes (34\%). El valor de la mediana de la PCR-us en los pacientes que presentaron EC fue de $4,49 \mathrm{mg} / \mathrm{l}$, frente a $4,48 \mathrm{mg} / \mathrm{l}$ en aquellos libres de esta complicación $(\mathrm{p}=0,76)$. Tampoco vimos que los pacientes con niveles elevados de PCR-us requirieran durante su evolución tratamiento revascularizador (Angioplastia, implantación de Stent o Cirugía coronaria) con más frecuencia que los presentaban niveles normales de dicho marcador. Un total de 21 de los 46 (46\%) pacientes del grupo que presentó niveles elevados de PCR-us requirió intervencionismo: 5 angioplastia, 11 angioplastia e implantación de Stent y 5 cirugía de revascularización coronaria, frente a 5 de 15 (33\%) de aquellos con niveles de PCR-us dentro de la normalidad: 1 angioplastia y 4 angioplastias con implantación de Stent $(\mathrm{p}=0,55)$.
TABLA IV

COM PLICACIO NES EVO LUTIVAS EN EL SCA AL AÑO DE SEGUIM IENTO

\begin{tabular}{lcccc}
\hline & SCA & IAM & AI & p \\
\hline Pacientes & 61 & $15(25)$ & $46(75)$ & \\
Exitus & $4(7)$ & $1(6)$ & $3(6)$ & ns \\
IAM & $9(15)$ & $3(20)$ & $6(13)$ & ns \\
Isquemia refractaria & $11(18)$ & $3(20)$ & $8(17)$ & ns \\
Rehospitalización & $6(10)$ & $0(0)$ & $6(13)$ & ns \\
ACV & $1(1,5)$ & $0(0)$ & $1(2)$ & ns \\
Evento combinado & $21(34)$ & $5(33)$ & $16(35)$ & ns \\
Revascularización & $26(43)$ & $5(33)$ & $21(46)$ & ns \\
$\quad$ ACTP & $6(10)$ & $1(7)$ & $5(11)$ & \\
\multicolumn{1}{r}{ ACTP+Stent } & $15(25)$ & $4(27)$ & $11(24)$ & \\
\multicolumn{1}{r}{ Cirugía coronaria } & $5(8)$ & $0(0)$ & $5(11)$ & \\
\hline
\end{tabular}

Valores expresados en número absoluto y porcentaje.

ACV: Accidente vascular cerebral. ACTP: Angioplastia coronaria transluminal percutánea. IAM : Infarto agudo de miocardio. PCR-us: proteína C-reactiva ultrasensible.

Cuando se analizó la aparición del EC al año mediante curvas de Kaplan-Meier, la PCR-us no mostró valor pronóstico. No hubo mayor incidencia de complicaciones entre aquellos que tuvieron valores de PCR-us elevados $(>2$ $\mathrm{mg} / \mathrm{l}$ ), frente a los que mostraron niveles normales (Fig. 2) (Tabla IV). Tampoco se apreciaron diferencias estadísticamente significativas al comparar la aparición de estas complicaciones entre grupos de pacientes con valores los valores de PCR-us por encima o debajo de la mediana, ni entre cuartiles superiores e inferiores. Al igual que para la PCRus, el resto de marcadores no se asociaron a complicaciones evolutivas.

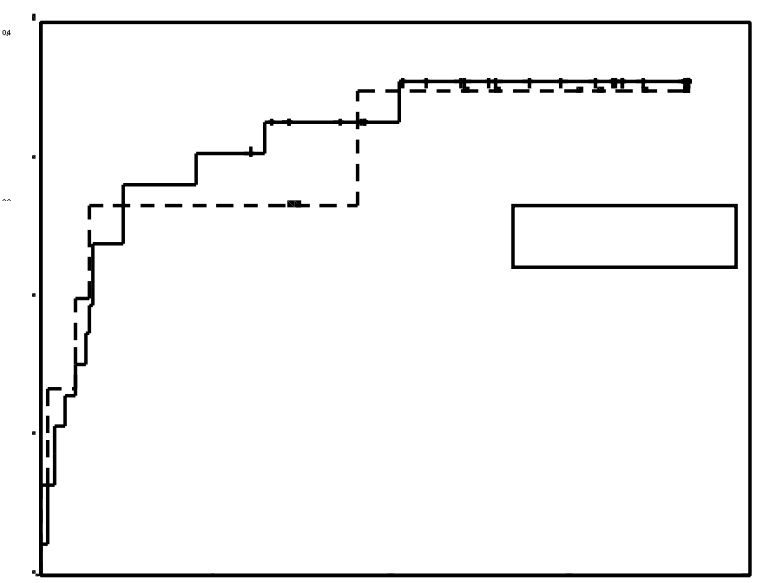

Fig. 2.Curvas de Kaplan-M eier de Incidencia acumulada del Evento Combinado (primera aparición de: muerte de origen cardiaco, reinfarto, isquemia refractaria o rehospitalización de causa cardiaca), en función de la proteína C-reactiva ultrasensible. Valor de PCR-us $\leq 2$ $\mathrm{mg} / \mathrm{l}$. (----) versus $>2 \mathrm{mg} / \mathrm{l}$ (_-_-_). 


\section{DISCUSIÓN}

Actualmente la actividad inflamatoria se encuentra en el centro de la patogenia de la aparición y evolución de la placa de ateroma y la cardiopatía isquémica (1-3, 29-30). Múltiples estudios han relacionado la cardiopatía isquémica estable e inestable con cifras elevadas de marcadores inflamatorios, entre ellos la PCR, y han demostrado su valor predictivo sobre la aparición de complicaciones cardiovasculares en pacientes con cardiopatía y en la población general (20-21). La PCR juega un papel fundamental como factor de riesgo vascular y probablemente en un futuro en la estratificación de riesgo y tratamiento en la cardiopatía isquémica (31). Los sistemas estándar de medición de la PCR carecen de la sensibilidad necesaria para determinar niveles de inflamación por debajo de límites normales que nos resulten útiles en la detección de pacientes de riesgo. Sin embargo, en el momento actual disponemos de métodos analíticos de alta sensibilidad capaces de detectar niveles bajos de este reactante de fase aguda con valor predictivo en la cardiopatía isquémica (32-34), aunque todavía no se ha extendido su uso rutinario en los hospitales.

En nuestro trabajo, hemos evidenciado una actividad inflamatoria aumentada en los pacientes que ingresan con un proceso coronario isquémico agudo e inestable sin elevación del segmento ST, de forma que 46 de los 61 pacientes (el $75 \%$ ) de nuestros casos mostraron valores elevados de PCRus, prototipo de reactante de fase aguda en los fenómenos inflamatorios.

El aumento de las cifras de PCR en el seno de la cardiopatía isquémica viene determinado por varios mecanismos fisiopatológicos. La inflamación está en el origen de la arterioesclerosis, pero también como consecuencia de la isquemia y la necrosis podrían incrementarse los niveles de marcadores inflamatorios, aunque este punto no está demostrado completamente (15). A este respecto, Liuzio y colaboradores vieron que las cifras de PCR se encuentran elevadas en los pacientes con infarto agudo de miocardio en fases precoces cuando los marcadores de necrosis miocárdica son todavía negativos lo que indica que el incremento de este marcador no depende de la existencia de necrosis (6). Sin embargo, se ha visto que en el área de necrosis miocárdica se produce una respuesta inflamatoria local a través de la activación del complemento mediada por la acción de la PCR (35). Por otra parte, en pacientes con angina variante y episodios de isquemia miocárdica transitoria sin necrosis no se objetivó elevación de PCR (36). Un estudio reciente confirma un aumento de las cifras PCR en aquellos pacientes con síndrome coronario agudo frente a los que presentaron cardiopatía isquémica estable, e incluso muestra que este estado de inflamación es mayor en los pacientes que presentan IAM con segmento ST persistentemente elevado versus la cardiopatía isquémica inestable sin elevación del ST (37). Sin embargo está poco estudiado dentro del SCA sin ascenso del segmento ST si un teórico mayor daño miocárdico acontecido en el IAM sin ascenso de ST frente al AI se traduce en un mayor incremento de PCR-us u otros marcadores. En esta línea, solamente hemos encontrado un estudio donde se analiza, aunque no como objetivo primario, la relación entre estos marcadores; Lindhal y cols. (13), en el seno del angor inestable (y previo al nuevo Consenso sobre la definición de Infarto Agudo de Miocardio (28)) no encontraron relación entre los niveles de PCR y la troponina, ambos se comportaban como marcadores independientes de riesgo, aunque con valor pronóstico aditivo. En nuestra serie no observamos diferencias entre ambos subgrupos (AI versus IAM sin elevación del ST) ni en lo referente al valor de la PCR-us ni tampoco en el porcentaje de pacientes con cifras por encima de la normalidad, presentando además una distribución uniforme los valores de PCRus en ambos subgrupos. Así pues no observamos que existiera mayor grado de inflamación en el IAM sin elevación del ST frente al AI, siendo la PCR-us poco sensible y específica para discriminar ambos cuadros. Respecto al resto de marcadores de inflamación, tampoco se objetivaron diferencias.

Finalmente, en referencia al valor pronostico de la PCRus y demás marcadores de inflamación sobre la aparición de complicaciones cardiovasculares en el seno de la cardiopatía isquémica, evidenciada en otros estudios (6,10-14,18-21), no hubo en nuestra serie ningún marcador que mostrase valor predictivo respecto a la aparición del EC (muerte de origen cardiaco, infarto o reinfarto, isquemia refractaria o rehospitalización) al año. No se apreciaron tampoco diferencias entre los diferentes cuartiles de PCR-us u otros marcadores. Tampoco vimos en nuestros pacientes que aquellos niveles altos de PCR-us precisasen intervencionismo coronario, a lo largo del seguimiento, en mayor medida que los pacientes con PCR-us normal.

Las principales limitaciones que encontramos en nuestro estudio son dos. En primer lugar el tamaño reducido de la muestra, principalmente en lo referente al subgrupo diagnosticado de angor inestable, en el que tan solo se incluyeron 14 pacientes. Sin embargo no pensamos que esto haya influido de forma definitiva en la ausencia de diferencias entre IAM sin ascenso ST y AI, ya que los resultados que mostraron ambos subgrupos respecto a los valores de PCR-us fueron muy homogéneos. Si es probable que influyera sin embargo en la ausencia de valor predictivo de complicaciones y una muestra reducida como esta no tenga poder estadístico suficiente en este sentido. Sin embargo otros trabajos relevantes han demostrado, con muestras incluso menores, el valor pronóstico de la PCR en el seno de la cardiopatía isquémica con un objetivo combinado primario similar al nuestro (6).

En segundo lugar, no contamos con controles analíticos seriados de la PCR-us para valorar su evolución temporal, la influencia del tratamiento administrado y si la persistencia de niveles elevados en el tiempo pudiera tener relación con la aparición del EC. Sin embargo este punto no fue uno de nuestros objetivos al diseñar el estudio.

\section{CONCLUSIONES}

1. Los pacientes con SCA sin elevación del segmento ST presentan un estado inflamatorio sistémico aumentado, como viene reflejado fundamentalmente por la elevación de la PCR-us.

2. No encontramos niveles diferentes de PCR-us, ni del resto de marcadores estudiados, entre IAM sin elevación ST y el AI, lo que parece reflejar un grado similar de inflamación en ambas entidades y que un teórico mayor daño miocárdico presente en el caso del IAM no está relacionado con un aumento de estos marcadores.

3. En nuestro reducido grupo de pacientes los diferentes marcadores de inflamación analizados, y en concreto la PCRus, no mostraron valor predictivo sobre la aparición de eventos cardiacos al año de seguimiento. 


\section{Bibliografía}

1. Ross R. Atherosclerosis. An inflammatory disease. N Engl J Med 1999; 340: 115-26.

2. Libby P. Molecular bases of the acute coronary syndromes. Circulation 1995; 91: 2844-50.

3. García-Moll X, KasKi JC. Cardiopatía isquémica: marcadores de inflamación y riesgo cardiovascular. Rev Esp Cardiol 1999; 52: 990-1003.

4. De Beer FC, Hind CR, Fox KM, Allan RM, Maseri A, Pepys MB. Measurement of serum $\mathrm{C}$-reactive protein concentration in myocardial ischaemia and infarction. Br Heart J 1982; 47: 239-43.

5. Berk BC, Weintraub WS, Alexander RW. Elevation of C-reactive protein "active" coronary artery disease. Am J Cardiol 1990; 65: 168-72.

6. Liuzzio G, Biasucci LM, Gallimore JR, Grillo RL, Rebuzzi AG, Pepys $\mathrm{MB}$, et al. The prognostic value of C-reactive protein and serum amyloid A protein in severe unestable angina. N Engl J Med 1994; 331: 417-24.

7. Ridker PM, Cushman M, Stampfer MJ, Tracy RP, Hennekens CH. Inflammation, aspirin and the risk of cardiovascular disease in apparently healthy men. N Engl J Med 1997; 336: 973-9.

8. Ridker PM, Buring JE, Shih J, Matias M, Hennekens CH. Prospective Study of C-Reactive Protein and the risk of future cardiovascular events among apparently healthy women. Circulation 1998; 98: 731-733.

9. Kuller LH, Tracy RP, Shaten J, Meilah EN. Relation of C-Reactive protein and coronary hearth disease in the MRFIT nested case-control study. Am J Epidemiol 1996; 144: 537-47.

10. Haverkate F, Thompson SG, Pyke S, Gallimore JR, Pepys MB. Production of C-reactive protein and risk of coronary events in stable and unstable angina. Lancet 1997, 349: 462-6.

11. Biasucci LM, Liuzzo G, Grillo RL, Caligiuri G, Rebuzzi AG, Buffon A, et al. Elevated levels of C-reactive protein at discharge in patients with unstable angina predict recurrent instability. Circulation 1999; 99: 855-60.

12. Anderson JL, Carlquist JF, Muhlestein JB, Horne BD, Elmer SP. Evaluation of C-reactive protein, an inflammatory marker, and infectious serology as risk factors for coronary artery disease and myocardial infarction. J Am Coll Cardiol 1998; 32: 35-41.

13. Lindahl B, Toss H, Siegbahn A, Venge P, Wallentin L. Markers of myocardial damage and inflammation in relation to long-term mortality in unstable coronary artery disease. N Engl J Med 2000; 343: 1139-47.

14. Heeschen C, Hamm CW, Bruemmer J, Simmons ML. Predictive Value of C-Reactive Protein and Troponin $\mathrm{T}$ in patients with unstable angina: a comparative analysis. J Am Coll Cardiol 2000; 35: 1535-42.

15. Lagrand WK, Visser CA, Hermens WT, Niessen HW, Verheugt FW, Wolbink GJ, et al. C-reactive protein as a cardiovascular risk factor. More than a epiphenomenon?. Circulation 1999; 100: 96-102.

16. Rifai N, Ridker PM. High-Sensitivity C-reactive protein: a novel and promising marker of coronary heart disease. Clin Chem 2001; 47: 403-11.

17. Kervinen H, Palosuo T, Manninen V, Tenkanen L, Vaarala O, Manttari M. Joint effects of C-reactive protein and other risk factors on acute coronary events. Am Heart J 2001; 141: 580-5.

18. Bazzino O, Ferreiros E, Pizarro R, Corrado G. C-reactive protein and stress test for the risk stratification of patients recovering from unstable angina pectoris. Am J Cardiol 2001; 87: 1235-9.

19. Toss H, Lindahl B, Siegbahn A, Wallentin L. Prognostic influence of increased fibrinogen and C-reactive protein levels in unstable coronary artery disease. Circulation 1997; 96: 4204-10.

20. Danesh J, Collins R, Appleby P, Peto R. Association of fibrinogen, Creactive protein, albumin, or leukocyte count with coronary heart disease. JAMA 1998; 279: 1477-82.
21. Danesh J, Whincup P, Walker M, Lennon L, Thomson A, Appleby P, et al. Low grade inflammation and coronary heart disease: prospective study and updated meta-analyses. BMJ 2000; 321: 199-204.

22. Kennon S, Price CP, Mills PG, Ranjadayalan K, Cooper J, Clarke H, et al. The effect of aspirin on $\mathrm{C}$-reactive protein as a marker of risk in unstable angina. J Am Coll Cardiol 2001; 37: 1266-70.

23. Ridker PM, Rifai N, Pfeffer MA, Sacks FM, Moye LA, Goldman S, et al. Inflammation, pravastatin, and the risk of coronary events after myocardial infarction in patients with average cholesterol levels. Circulation 1998; 98: 839-44.

24. Ridker PM, Rifai N, Pfeffer MA, Sacks FM, Braunwald E. Long-term effects of pravastatin on plasma concentration of C-reactive protein. Circulation 1999; 100: 230-5.

25. Jialai I, Stein D, Balis D, Grundy SM, Adams-Huet B, Devaraj S. Effect of hydroxymethyl glutaryl coenzyme A reductase inhibitor therapy on high sensitive C-reactive protein levels. Circulation 2001; 103: 1933-5.

26. Ridker PM, Rifai N, Clearfield M, Downs JR, Weis SE, Miles JS, et al. Measurement of C-reactive protein for the targetin of statin therapy in the primary prevention of acute coronary events. N Engl J Med 2001; 344: 1959-65.

27. Albert MA, Danielson E, Rifai N, Ridker PM. Effect of statin therapy on $\mathrm{C}$-reactive protein levels. The Pravastatin Inflammation/CRP evaluation (PRINCE): A randomized trial and cohort study. JAMA 2001. 286: 6470.

28. Alpert JS, Thygesen K, Antman E, Bassand JP, et al. Myocardial Infarction Redefined- A Consensus Document of the Joint European Society of Cardiology/ American College of Cardiology Commitee for the Redefinition of Myocardial Infarction. J Am Coll Cardiol 2000; 36: 959-69.

29. Libby P. Current concepts of the pathogenesis of the acute coronary syndromes. Circulation 2001; 104: 365-72.

30. Kaski JC. Inflamación, infección y enfermedad coronaria: mitos y realidades. Conferencia especial del XXXV Congreso Nacional de la Sociedad Española de Cardiología. Rev Esp Cardiol 2000; 53: 1311-7.

31. Ridker PM. High-sensitivity C-Reactive Protein. Potential adjunct for global risk assessment in the primary prevention of cardiovascular disease. Circulation 2001; 103: 1813-8.

32. Ledue TB, Weiner DL, Sipe JD, Poulin SE, Collins MF, Rifai N. Analytical evaluation of particle-enhaced immunonephelometric assays for CReactive protein, serum amyloid A and manose-binding protein in human serum. Ann Clin Biochem 1998; 35: 745-53.

33. Roberts WL, Sedrik R, Moulton L, Spencer A, Rifai N. Evaluation of four automated high-sensitivity C-reactive protein methods: Implications for clinical and epidemiological aplications. Clin Chem 2000; 46: 461-8.

34. Roberts WL, Moulton L, Law TC, Farrow G, Cooper-Anderson M, Savory J, et al. Evaluation of nine automated High-sensitivity C-Reactive protein methods: Implications for clinical and epidemiological applications. Part 2. Clin Chem 2001; 47: 418-25.

35. Lagrand WK, Niessen HWM, Wolbink GJ, Jaspars LH, Visser CA, Verheught FWA, et al. C-reactive protein colocalizes with complement in human hearts during acute myocardial infarction. Circulation 1997; 95 : 97-103.

36. Liuzzio G, Biasucci LM, Rebuzzi AG, Gallimore R, Caligiuri G, Lanza GA, et al. Plasma protein acute-phase response in unstable angina is not induced by ischemic injury. Circulation 1996; 94: 2373-80.

37. Bermejo J, Martínez P, Martín JF, De la Torre M, Bustamante R, Guerrero A, et al. Inflamación e infección en la enfermedad coronaria estable y en el síndrome coronario agudo. Rev Esp Cardiol 2001; 54: 453-9. 